\title{
Publisher Correction: Past and future spread of the arbovirus vectors Aedes aegypti and Aedes albopictus
}

Moritz U. G. Kraemer (iD, Robert C. Reiner Jr, Oliver J. Brady, Jane P. Messina, Marius Gilbert, David M. Pigott, Dingdong Yi, Kimberly Johnson, Lucas Earl, Laurie B. Marczak, Shreya Shirude, Nicole Davis Weaver DD, Donal Bisanzio, T. Alex Perkins, Shengjie Lai, Xin Lu, Peter Jones, Giovanini E. Coelho, Roberta G. Carvalho, Wim Van Bortel (D, Cedric Marsboom, Guy Hendrickx, Francis Schaffner, Chester G. Moore, Heinrich H. Nax, Linus Bengtsson, Erik Wetter DiD, Andrew J. Tatem, John S. Brownstein, David L. Smith (D), Louis Lambrechts (D), Simon Cauchemez, Catherine Linard (D), Nuno R. Faria (D), Oliver G. Pybus, Thomas W. Scott, Qiyong Liu, Hongjie Yu, G. R. William Wint, Simon I. Hay D and Nick Golding (D)

Correction to: Nature Microbiology https://doi.org/10.1038/s41564-019-0376-y, published online 4 March 2019.

In the version of this Article originally published, the affiliation for author Catherine Linard was incorrectly stated as ' ${ }^{6} \mathrm{Department}$ of Infectious Disease Epidemiology, London School of Hygiene and Tropical Medicine, London, UK'. The correct affiliation is '9 Spatial Epidemiology Lab (SpELL), Universite Libre de Bruxelles, Brussels, Belgium. The affiliation for author Hongjie Yu was also incorrectly stated as ${ }^{11}$ Department of Statistics, Harvard University, Cambridge, MA, USA' The correct affiliation is ' ${ }^{15}$ School of Health, Fudan University, Key Laboratory of Public Health Safety, Ministry of Education, Shanghai, China'. This has now been amended in all versions of the Article.

Open Access This article is licensed under a Creative Commons Attribution 4.0 International License, which permits use, sharing, adaptation, distribution and reproduction in any medium or format, as long as you give appropriate credit to the original author(s) and the source, provide a link to the Creative Commons license, and indicate if changes were made. The images or other third party material in this article are included in the article's Creative Commons license, unless indicated otherwise in a credit line to the material. If material is not included in the article's Creative Commons license and your intended use is not permitted by statutory regulation or exceeds the permitted use, you will need to obtain permission directly from the copyright holder. To view a copy of this license, visit http://creativecommons.org/
} licenses/by/4.0\%

Published online: 21 March 2019

https://doi.org/10.1038/s41564-019-0429-2

(C) The Author(s) 2019 